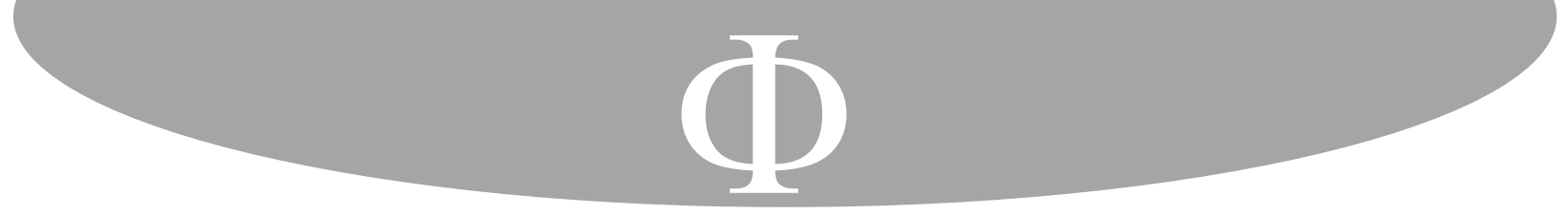

\title{
Raíces y componentes esenciales del análisis pragmalingüístico de la Escritura
}

(1) (2)

Para citar este artículo: Jiménez Romero, Juan Carlos. «Raíces y componentes esenciales del análisis pragmalingüístico de la Escritura». Franciscanum 177, Vol. 64 (2022): 1-35.

Juan Carlos Jiménez Romero*

Pontificia Universidad Javeriana

Bogotá, Colombia

\section{Resumen}

Este artículo de revisión descriptiva aborda las bases teóricas del método pragmalingüístico en cuanto aplicable a la exégesis de los textos bíblicos. En un primer momento explica sus raíces y marcos teóricos, presentando su fundamento desde pensadores y estudiosos de la lingüística y la filosofía del lenguaje, para luego concentrar la atención en sus tareas o competencias básicas: la influencia del contexto sobre el texto y de este sobre el contexto. Se constituye en una síntesis bastante consistente a la hora de fundamentar propuestas de investigación exegética que se realicen en este espectro interpretativo.

\section{Palabras clave}

Proceso de comunicación, filosofía del lenguaje, pragmática, análisis pragmalinguiístico, texto y contexto.

\section{Origin and essential components of the Pragmalinguistic analysis of the Holy Scripture}

\section{Summary}

This descriptive review article addresses the theoretical bases of the pragmalinguistic method as applicable to the exegesis of biblical texts. At first it explains its roots and theoretical frameworks, presenting its foundation from thinkers and scholars of linguistics and the philosophy of language, and then concentrates attention on its tasks or basic competences: the influence of the context on the text and this on the context. It constitutes a fairly consistent synthesis when it comes to substantiating exegetical research proposals that are carried out in this interpretive spectrum.

\footnotetext{
* Bachiller en Teología, Pontificia Universidad Javeriana, Bogotá; Licenciado en Filosofía y Educación Religiosa, Universidad Santo Tomás, Bogotá; Licenciado en Teología con Especialidad Bíblica, Pontificia Universidad Gregoriana, Roma (convalidado por el Ministerio de Educación de Colombia como Maestría). Doctor en Teología, Pontificia Universidad Javeriana, Bogotá. Sacerdote de la Diócesis de Garagoa, Boyacá Colombia. ORCID: http://orcid.org/0000-0002-7520-3051. Contacto: jucajiro25@yahoo.com.
} 


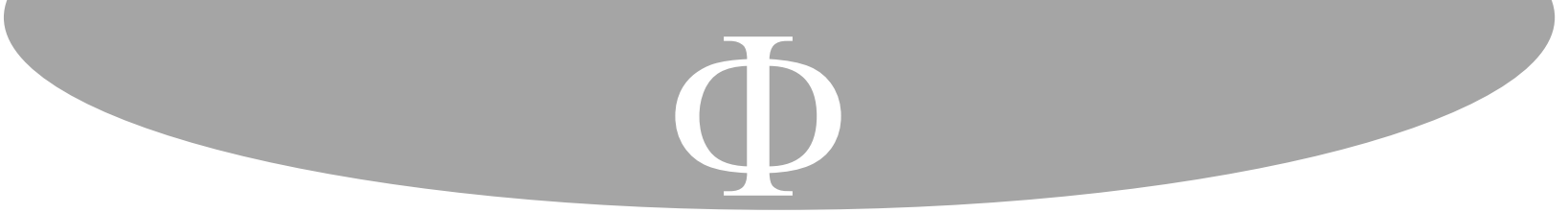

Como punto de partida, vale la pena considerar la etimología del término pragmalingüística. Proviene del griego pragma, que significa «acción», y a su vez, «es una raíz común a diversas etiquetas de corrientes filosóficas que tiene como objeto el estudio del actuar humano» ${ }^{6}$. Para este escrito, el interés surge por una particular forma de acción: el actuar lingüístico. Así, «el objetivo no es indagar la acción humana en general, sino investigar aquella forma particular de acción que es el uso del lenguaje, y comprender cómo ésta pueda constituir un medio (o parte integral) del actuar humano en general» ${ }^{7}$.

Ahora bien, interesarse por el uso del lenguaje, implica asumir como presupuesto que este «es el medio a través del cual el hombre expresa su mundo interior, denomina las cosas, ordena lo existente, relata historias; en una palabra, comunica, por lo que la comunicación se constituye en la función primaria del lenguaje» ${ }^{8}$. Este hecho obliga a situar la pragmática en el marco de exploración del fenómeno de la comunicación, que, por darse de una manera espontánea y cotidiana, pareciera una actividad simplísima ${ }^{9}$, pero no siempre resulta así ${ }^{10}$.

Será desde la perspectiva de distintas áreas del conocimiento, interesadas en el fenómeno de la comunicación humana y en el lenguaje como instrumento privilegiado que la posibilita, que se tomarán en consideración los principales hallazgos de sus protagonistas a favor de la pragmática. Para ello, se destacará la semiótica, la lingüística y, muy cercana a ella, la filosofía del lenguaje.

Así pues, desde el campo de la filosofía y la semiótica, el americano Charles Morris (1938) introdujo el denominativo "pragmática» en distinción con las otras dos ramas de la semiótica: la sintaxis y la semántica ${ }^{11}$. Esto lo hizo a partir de las relaciones básicas de los signos: a la sintaxis le corresponde el estudio de las relaciones de los signos (las palabras)

\footnotetext{
${ }^{6}$ Filippo Domaneschi, Introduzione alla pragmática (Roma: Carocci editore, 2014), 18-19; ver Stephen C. Levinson, Pragmatics (New York: Cambridge University Press, 1994), 2-3. Algunos estudiosos consideran la pragmática no como una disciplina autónoma, sino como una perspectiva o un ámbito de investigación interdisciplinar que atraviesa las diversas áreas del conocimiento (con las que se da un enriquecimiento mutuo): filosofía del lenguaje, lingüística, antropología, sociología, psicología, retórica, entre otras. Claudia Bianchi, Pragmatica del linguaggio (Bari: Laterza, 2010), 12; Massimo Grilli, «Interpretazione e azione. L’istanza pragmatica del testo biblico», en Comunicazione e pragmatica nell'esegesi biblica, ed. Massimo Grilli, Maurizio Guidi y Elzbieta M. Obara (Milano-Roma: San Paolo - Gregorian \& Biblical Press, 2016), 25-26.

7 Filippo Domaneschi, Introduzione alla pragmática, 19. (La cursiva no es del autor). «La perspectiva pragmática es un intento de echar luz sobre más fenómenos para entender mejor cómo funciona la lengua en la realidad cotidiana de la vida: el cómo, qué, por qué, para qué de nuestros incesantes discursos». Graciela Reyes, La pragmática. El estudio del uso del lenguaje (Barcelona: Montesinos, 1990), 42.

${ }^{8}$ Massimo Grilli, «Interpretazione e azione», 15-16.

9 «Nos comunicamos con palabas o con escritos, con gestos o muecas, con modos de hacer, de vestir, de comportarse; nos comunicamos usando objetos, la mirada, la sonrisa, el silencio, un puntapié bajo la mesa o palmadas en la espalda. Nos comunicamos con una facilidad y un grado de éxito extraordinario». Claudia Bianchi, Pragmatica del linguaggio, 3.

${ }^{10}$ Cuando los malentendidos aparecen en la cotidianidad, estos se convierten en oportunidad para reflexionar sobre «la riqueza y la complejidad del lenguaje y de los mecanismos comunicativos». Claudia Bianchi, Pragmatica del linguaggio, 3.

${ }^{11}$ Charles Morris, Fundamentos de la teoría de los signos (Barcelona: Paidós, 1985), 31-32.
} 


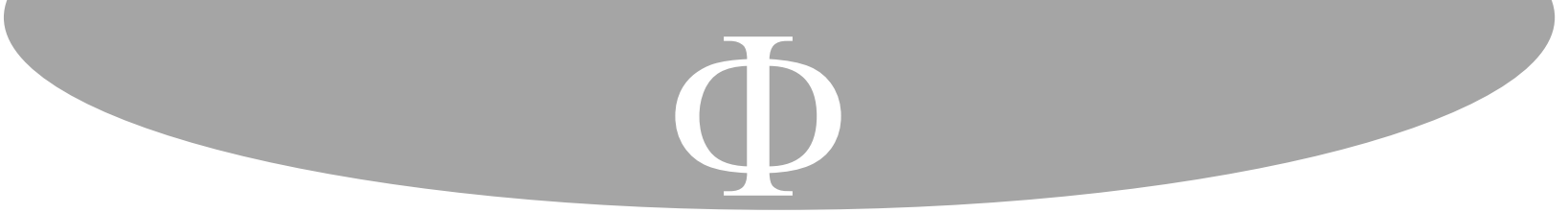

\subsubsection{Soporte teórico desde la filosofía del lenguaje}

Partiendo de la iniciativa original de Morris (1938), quien comprendió la pragmática como el estudio de los aspectos del lenguaje que requieren una referencia a los usuarios de este, hasta Domaneschi (2014), quien sintetizó la amplia comprensión de Levinson (1983), es importante anotar que este proceso de profundización y enriquecimiento de la pragmática se debe a la importancia que la filosofía del lenguaje ${ }^{22}$ le ha dado. Es entonces desde esta mirada que, se entran a considerar los aportes de los principales filósofos que han venido dando un fuerte soporte teórico, y configurando los aspectos específicos de la pragmática como metodología de análisis del lenguaje y en particular de los Escritos Sagrados.

A este respecto, es válido afirmar que el principal impulso proviene de una marcada diferencia entre dos corrientes de la filosofía del lenguaje que podrían caracterizarse como filosofía del lenguaje ideal y filosofía del lenguaje ordinario ${ }^{23}$, en los años setenta. La primera, "se ocupaba prevalentemente de los lenguajes formales con el objetivo de crear un lenguaje perfecto -un lenguaje ideal-, privado de los defectos y de las ambigüedades de los lenguajes naturales (las lenguas cotidianas) ${ }^{\prime 24}$. Desde esta propuesta, se debería dar paso a la creación de una teoría semántica rigurosa, capaz de ser un instrumento absolutamente confiable para el trabajo científico y filosófico, y que, por lo tanto, privilegiara la dimensión descriptiva y representativa del lenguaje. Esta mirada, daba prioridad al significado literal: la verdad o falsedad dependería de su estricta correspondencia con el mundo ${ }^{25}$.

A este modo de concebir el lenguaje (con una semántica rigurosa), se contrapone la mirada de los filósofos del lenguaje ordinario, entre los que se destacan: el segundo Wittgenstein $^{26}$, Friedrich Waismann, John L. Austin, Paul Grice, Peter Strawson, y

por consiguiente en relación a sus usuarios; ella examina las acciones linguísticas (actos de palabra), o bien las enunciaciones comunicativas, teniendo en cuenta los contextos y las situaciones de palabra en las cuales ellas son colocadas; trata de esclarecer la relación entre las proposiciones y sus manifestaciones en los actos del habla». Schmidt, Teoria, 52, citado por Cesar Mora, «Los métodos de Análisis Literario: el método pragmalingüístico», 63)

${ }^{22}$ Stephen C. Levinson, Pragmatics, 3.

${ }^{23}$ Claudia Bianchi, Pragmatica del linguaggio, 12; Filippo Domaneschi, Introduzione alla pragmática, 22-23. Si se quiere ir a las raíces de esta doble perspectiva, es necesario retornar al pensamiento de los filósofos clásicos, cuya diferencia de perspectivas marcó las principales corrientes de la historia: Platón ponía en evidencia que «el decir es una acción». Platón, Cratilo o Del lenguaje, Ed. Artilano Domínguez (Madrid: Trotta, 2002), 387c, mientras que Aristóteles, reconociendo la existencia de discursos no apofácticos como la oración o la recitación, sostenía que la lógica debía ocuparse exclusivamente del lenguaje declarativo o apofáctico: el lenguaje que puede ser valorado como verdadero o falso. Filippo Domaneschi, Introduzione alla pragmática, 192; Véase Genaro Carrió y Eduardo Rabossi, «La Filosofía de John L. Austin» (Barcelona: Paidós, 1991), 1415.

${ }^{24}$ Claudia Bianchi, Pragmatica del linguaggio, 12-13. A esta corriente pertenecen Gottlob Frege, Bertrand Russell, Ludwig Wittgenstein, Alfred Tarski e Willard Quine. Donald Davidson y Richard Montague se podrían agregar posteriormente. Claudia Bianchi, Pragmatica del linguaggio.

${ }^{25}$ Claudia Bianchi, Pragmatica del linguaggio, 13-14.

${ }^{26}$ Es importante indicar que se habla del segundo Wittgenstein para hacer referencia al pensamiento expresado en sus obras «Cuadernos azul y marrón» e «Investigaciones Filosóficas», en diferencia con el primer Wittgenstein, cuyo pensamiento está plasmado principalmente en «Tractatus Logico-Philosophicus». 


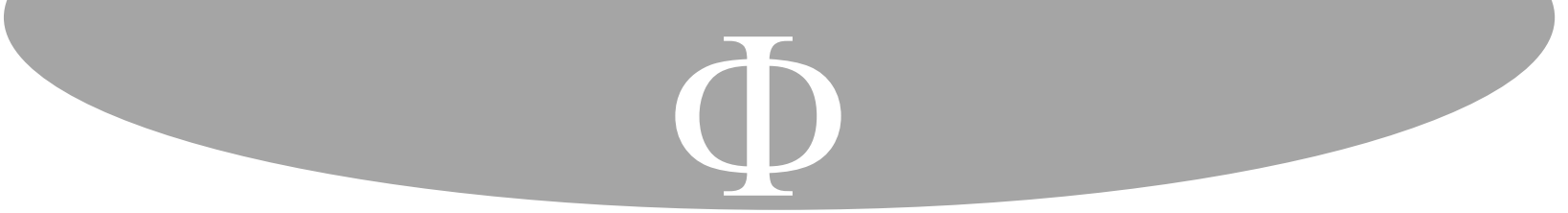

tardíamente John R. Searle. Para ellos, la elasticidad y las ambigüedades ${ }^{27}$ del lenguaje natural, cotidiano, lejos de ser considerados como defectos, son signos de su riqueza, poder expresivo y capacidad de adaptarse a nuevos contextos y circunstancias insólitas ${ }^{28}$.

La atención no se centra en la frase, en cuanto unidad gramatical que representa un estado de las cosas, sino en el hablante que se sirve de la frase para decir o enunciar algo. En esta corriente, se enfatiza en la diversidad de las funciones que los enunciados pueden ejercer en el lenguaje natural: afirmaciones, órdenes, peticiones, entre otros, que se sintetizan en la célebre tesis de Austin: "decir algo es hacer algo» ${ }^{29}$. Así, los enunciados no tienen un sentido estrictamente cognitivo, sino pragmático: sirven para cumplir verdaderos y propios actos ${ }^{30}$.

Como se acaba de insinuar, uno de los aportes más sólidos sobre el reconocimiento y la comprensión de la pragmática lo enfatizó John Langshaw Austin ${ }^{31}$, quien introdujo el concepto de acto performativo o realizativo, en oposición al de acto constatativo ${ }^{32}$, para indicar que «se sigue una acción en el acto mismo de proferir un enunciado: (...) con un acto performativo no se limita a describir algo que existe en el mundo externo, sino que se actúa sobre este» ${ }^{33}$. Con el tiempo, Austin revisó y ajustó su propuesta hasta configurar una teoría más amplia llamada teoría de los actos lingüísticos. En esta, desaparece la bipartición entre «constatativos»y «performativos» ${ }^{34}$, afirmando que «todos los enunciados, más allá de contener un significado, cumplen una función de verdaderas y propias acciones, dada la presencia del elemento performativo en todo uso del lenguaje» ${ }^{35}$. Además, afirma la presencia de «tres sentidos en los que decir es hacer algo: distinguiendo así el acto locutivo que posee significado, el acto ilocutivo que posee una cierta fuerza al decir algo, y el acto perlocutivo que consiste en lograr ciertos efectos por (el hecho de) decir algo» ${ }^{36}$.

\footnotetext{
27 «Una expresión es ambigua cuando puede tomar convencionalmente dos o más significados». Claudia Bianchi, Pragmatica del linguaggio, 25.

${ }^{28}$ Genaro Carrió y Eduardo Rabossi, «La Filosofía de John L. Austin», 11; Claudia Bianchi, Pragmatica del linguaggio, 14-16.

${ }^{29}$ John L. Austin, Cómo hacer cosas con palabras. Palabras y acciones (Barcelona: Paidós, 1991), 51 y 57.

${ }^{30}$ Claudia Bianchi, Pragmatica del linguaggio, 14-16; Genaro Carrió y Eduardo Rabossi, «La Filosofía de John L. Austin», 32.

${ }^{31}$ John L. Austin, en su corta vida, no dejo muchos escritos, de hecho, el más famoso es How to Do Things with Words - 1962 (Cómo hacer cosas con palabras). Este fue póstumo, pues no fue escrito directamente por él, sino que es editado a partir de las lecciones que tuvo en Harvard en 1955 y de múltiples conferencias y seminarios. Genaro Carrió y Eduardo Rabossi, «La Filosofía de John L. Austin», 9-10.

${ }^{32}$ Véase Austin, Cómo hacer cosas con palabras, 47-52. Un acto constatativo corresponde a una aserción (afirmación).

${ }^{33}$ Elzbieta M. Obara, «Le azioni linguistiche. L’influsso del testo sul contesto», en Comunicazione e pragmatica nell'esegesi bíblica, ed. Massimo Grilli, Maurizio Guidi y Elzbieta M. Obara (Milano-Roma: San Paolo Gregorian \& Biblical Press, 2016), 87; véase John L. Austin, Cómo hacer cosas con palabras, 57-58.

${ }^{34}$ John L. Austin, Cómo hacer cosas con palabras, 167.

35 Elzbieta M. Obara, «Le azioni linguistiche», 95; véase Carla Bazzanella, Linguistica e pragmatica del linguaggio. Un introduzione (Roma-Bari: GLF Laterza, 2007), 150.

${ }^{36}$ John L. Austin, Cómo hacer cosas con palabras, 167.
} 


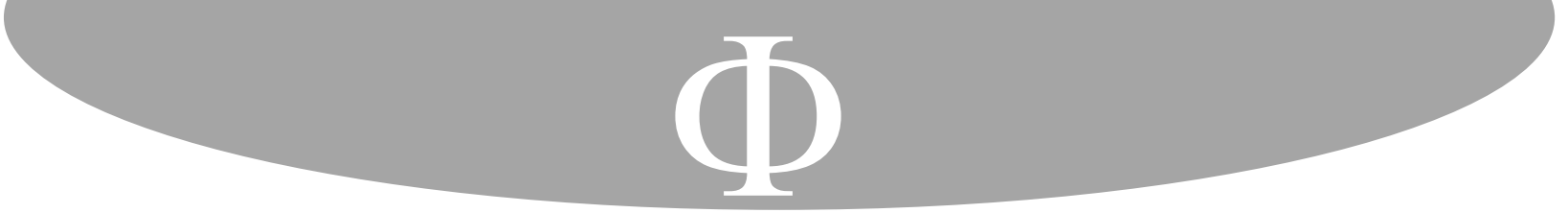

Sobre este planteamiento tripartito del acto lingüístico, se volverá más adelante, por el momento basta indicar que es en el aspecto ilocutivo del lenguaje donde mejor se manifiesta su carácter performativo. Y será precisamente allí, en la fuerza ilocutiva de los enunciados ${ }^{37}$, que su discípulo John R. Searle concentró sus esfuerzos e identificó cinco categorías en las que se podrían agrupar y tipificar los actos lingüísticos: representativos, directivos, comisivos, expresivos y declarativos ${ }^{38}$; clasificación que también será profundizada más adelante.

Otro gran filósofo es Herbert Paul Grice, quien es considerado uno de los padres fundadores de la pragmática, aunque nunca utilizó dicho término en sus escritos. De modo particular, se le atribuye la superación del conflicto entre la filosofía del lenguaje ideal y la filosofía del lenguaje ordinario, pues subrayó que no se trataba de dos percepciones distintas, sino del énfasis parcializado que cada una de ellas hacía de un elemento del lenguaje, en detrimento u omisión del otro. Mas bien, resultaría pertinente hacer una distinción objetiva entre lo que es el significado de las expresiones lingüísticas, que es invariable, y el uso de estas en determinadas circunstancias reales que dan posibilidad a diversos sentidos ${ }^{39}$. Se trata, por tanto, de dos componentes que integran una misma realidad lingüística, complementarios y no contrapuestos. Así, «una teoría del lenguaje debe tener en cuenta la semántica o significado de las expresiones y el uso efectivo que viene hecho de las expresiones lingüísticas, es decir, lo que hoy es comúnmente considerado objeto de estudio de la pragmática» ${ }^{40}$.

Ahora bien, entre los elementos particulares que Grice trabajó, se resaltan los siguientes en la configuración de lo que hoy es el análisis pragmalingüístico:

- Asociación del significado a la intención: la comunicación lingüística consiste en un proceso de producción y reconocimiento de intenciones comunicativas, ya que un hablante al decir un enunciado, dotado de sentido, tiene esencialmente dos finalidades: primero, producir en el destinatario un efecto mediante una determinada expresión y, segundo, lograr que este reconozca que el hablante quiere producir dicho efecto ${ }^{41}$. De este modo, «el significado del hablante corresponde a su intención comunicativa, es decir aquello que él intenta comunicar en una particular ocasión de uso, utilizando una determinada expresión lingüística» ${ }^{42}$.

\footnotetext{
${ }^{37}$ De la exposición que hace Austin, se entiende cierta carga o potencial que le da especificidad a los distintos tipos de función del lenguaje, en el que el contexto y la ocasión en que una expresión se emite tienen gran importancia. John L. Austin, Cómo hacer cosas con palabras, 146-147).

38 John Searle, Expression and Meaning. Studies in the Theory of Speech Acts (New York: Cambridge University Press, 1986), 12-20.

${ }^{39}$ Ver Filippo Domaneschi, Introduzione alla pragmática, 27.

${ }^{40}$ Filippo Domaneschi, Introduzione alla pragmática, 27-28. La ayuda de Grice para resolver el problema es, de alguna manera, una vuelta sobre la distinción que mucho antes hubiera planteado Morris entre las tres ramas de estudio de la lingüística: sintaxis, semántica y pragmática.

${ }^{41}$ Filippo Domaneschi, Introduzione alla pragmática, 30.

${ }^{42}$ Filippo Domaneschi, Introduzione alla pragmática, 32. El evento comunicativo se completa cuando el destinatario reconoce la intención. Filippo Domaneschi, Introduzione alla pragmática, 32.
} 


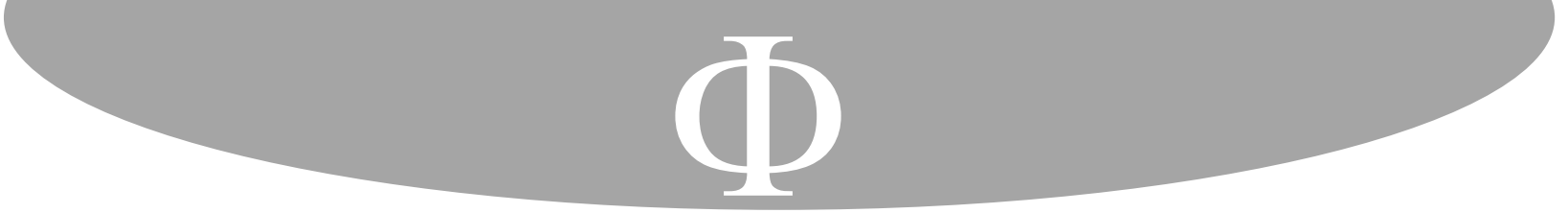

- Contribución a la superación del modelo tradicional de la comunicación: previo a la propuesta de Grice, este se entendía como un simple proceso de codificación y decodificación de mensajes, para luego considerarlo como «el fruto de inferencias llevadas a cabo por los hablantes sobre la base de indicios sea lingüísticos que no lingüísticos» ${ }^{43}$. Así pues, «un oyente, para comprender lo que un hablante intenta comunicar, debe siempre desarrollar más allá de la decodificación del significado de las expresiones- una inferencia basada sobre múltiples factores: la información inherente al mundo, el particular contexto en el que tiene lugar el intercambio comunicativo y los mismos interlocutores ${ }^{44}$.

Gracias a las propuestas de estos filósofos y de otros estudiosos del lenguaje, se sostiene el andamiaje teórico de la pragmalingüística. Basta aclarar que la pragmalingüística penetró en los métodos de interpretación bíblica para enriquecerles ampliamente, como se presenta a continuación.

\subsection{Cambios profundos en la exégesis bíblica en la segunda mitad del siglo XX 1.2.1 De la exégesis diacrónica a la sincrónica}

Recurriendo a la historia de la exégesis, no es un secreto que el paso de la exégesis medieval a la moderna estuvo marcado por el florecimiento de los llamados métodos histórico$\operatorname{críticos}^{45}$, centrados en el estudio del texto, su autor y sus antecedentes. Se trató de un movimiento impulsado por hechos que, en un primer momento, fueron motivo de crisis, pero que, luego, se convirtieron en causa de crecimiento: por una parte, la Reforma Protestante que lideró cambios en la percepción de la Escritura como alma de la teología, de la pastoral y la espiritualidad del pueblo de Dios; por otra, las criticas racionalistas del Renacimiento que se convirtieron en reto para la Iglesia Católica, cuyo primer gran fruto se daría con la encíclica Providentissimus Deus (1893) del papa Leon XIII. En esta, distinto a lo que muchos esperaban, el Papa no exhortó a los exégetas católicos a permanecer en los límites de una explicación espiritual de los textos, sino a adquirir una suficiente competencia científica, de modo que fuesen capaces de aventajar a los que estaban actuando como adversarios. Cincuenta años más tarde, el papa Pio XII, con la encíclica Divino Afflante Spiritu (1943), ratificó la estrecha unión entre el sentido espiritual y el sentido literal de la Escritura, admitiendo oficialmente los métodos histórico-críticos en el seno de la Iglesia ${ }^{46}$.

\footnotetext{
${ }^{43}$ Filippo Domaneschi, Introduzione alla pragmática, 35.

${ }^{44}$ Filippo Domaneschi, Introduzione alla pragmática, 38; véase Massimo Grilli, «Interpretazione e azione», 23-24.

${ }^{45}$ Se habla de métodos histórico-críticos, en plural, puesto que están estrechamente vinculados entre sí y en muchos casos aparecen dispuestos como diversos momentos o etapas del mismo proceso, pero cada uno de estos tiene sus propias técnicas y su propia finalidad. Además, todos no se desarrollan necesariamente en todos los procesos de estudio de un texto. Horacio Simian-Yofre, Metodología del Antiguo Testamento, 87.

${ }^{46}$ Véase Pontificia Comisión Bíblica, La interpretación de la Biblia en la Iglesia (Vaticano: El Vaticano, 1993), 8-9.24; Pio XII, Encíclica Divino Afflante Spiritu (Roma: 1943), consultada el 2 de febrero de 2018, https://w2.vatican.va/content/pius-xii/es/encyclicals/documents/hf_p-xii_enc 30091943 divino-afflantespiritu.html, 15-20. Para una mayor profundización sobre el paso de la exégesis medieval a la moderna y el paulatino florecimiento de los distintos métodos histórico-críticos. Véase Juan Carlos Jiménez, «Pertinencia del análisis pragmalingüístico», 396-404.
} 


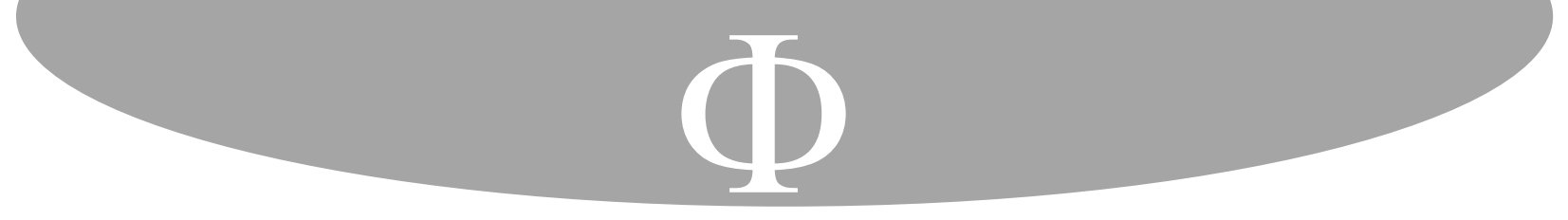

Paradójicamente, apenas la perspectiva diacrónica, que caracteriza a los métodos histórico-críticos y que habría sido la predominante en la exégesis moderna, recibió el reconocimiento eclesial, salieron a la luz distintas miradas metodológicas de tipo sincrónico, cuyo objeto era el análisis del texto final en sí mismo, en su cohesión y funcionamiento ${ }^{47}$. Además, su inserción en la exégesis católica no resultó difícil, sino más bien estimulada y sostenida por el Concilio Vaticano II, que reconoció el aporte de las ciencias en el desempeño de las tareas que le competen como Iglesia ${ }^{48}$, poniendo el acento en la Escritura como Palabra de Dios en palabras humanas ${ }^{49}$ e impulsando explícitamente a los exégetas a la utilización de los instrumentos oportunos en su investigación ${ }^{50}$.

Ahora, que la exégesis pasara de una mirada exclusivamente diacrónica a la valoración efectiva de una serie de métodos de tipo sincrónico, no significó que desconociera los grandes logros que por ella se obtienen, sobretodo, en la objetivación de aspectos de la revelación desde la solidez racional que se le dio a la interpretación de la Escritura ${ }^{51}$. Ciertamente, algunos métodos, como el estructuralista o semiótico, se sitúan en oposición a los históricocríticos al renunciar por completo al interés por el autor y a los posibles estadios anteriores de constitución de los relatos, para concentrarse en la observación del texto final en sus condiciones internas de significación, con atención particular a la forma o estructura del mensaje ${ }^{52}$. Pero, otros, como el narrativo, no nacen en reacción a las falencias de tales métodos, sino más bien, como en este caso, se trata del desarrollo de una parte de ellos, la crítica literaria ${ }^{53}$, que ciertamente adquiere un nuevo perfil en cuanto su interés no se concentra tanto en saber si el relato es o no histórico sino en el mérito y significado de la historia narrada ${ }^{54}$.

\footnotetext{
${ }^{47}$ Roland Meynet, Leggere la Bibbia. Un'introduzione all'esegesi (Bologna: EDB, 2004), 63. «El puesto que en el pasado ocupaba la investigación sobre el desarrollo histórico de los textos, ha sido en gran parte sustituido por el análisis literario del texto y su función hermenéutica». Massimo Grilli, «Interpretazione e azione», 1112 .

${ }^{48}$ Concilio Vaticano II, Constitución pastoral Gaudium et Spes (Vaticano: Vaticano, 1965), No. 44.

${ }^{49}$ Concilio Vaticano II, Constitución dogmática Dei Verbum (Vaticano: Vaticano, 1965), No. 12.

${ }^{50}$ Concilio Vaticano II, Constitución dogmática Dei Verbum, No. 23.

${ }^{51}$ Horacio Simian-Yofre, Metodología del Antiguo Testamento, 83; Juan Carlos Jiménez, «Pertinencia del análisis pragmalingüístico», 400. «Mientras uno más sepa de su desarrollo diacrónico [del texto bíblico], mejor entenderá su forma final; es decir, el análisis diacrónico y sincrónico no se excluyen, sino que ambos son necesarios para una recta comprensión». Ulrich Berges, «La lingüística pragmática como método de la exégesis bíblica», 70-71.

${ }^{52}$ Giroud y Panier, Semiótica: una práctica de lectura y análisis de los textos bíblicos (Estella: Verbo Divino, 1988), 7.

${ }^{53}$ Esto se da en particular con el New Criticism, que se difundía en los países anglosajones desde 1930, cuya principal preocupación consistía en volver sobre la obra literaria en su autonomía de «obra de arte», que ciertamente se ve enriquecida por la intención del autor, por la historia, y por elementos de la sociología y la psicología, entre otros. Jean-Pierre Sonnet, «L'analisi narrativa dei racconti biblici», en Manuale di esegesi dell'Antico Testamento, Comp. Michaela Bauks y Christophe Nihan (Bologna: EDB, 2010), 46.

${ }^{54}$ Jean-Pierre Sonnet, «L'analisi narrativa dei racconti biblici», 46.
} 


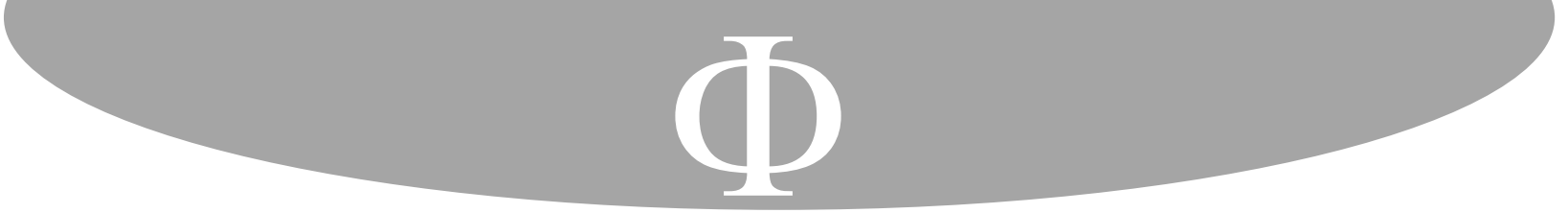

En estos casos, se trata de métodos adaptados desde teorías externas al campo bíblico, gestados tiempo atrás en el campo de la literatura o desde otras ciencias, que, al ser utilizados en el análisis de los escritos bíblicos, hallan gran aplicabilidad ${ }^{55}$. Sin embargo, se debe reconocer que, a su vez, se desarrollaba una perspectiva interpretativa propia de los escritos y la mentalidad que permea los relatos bíblicos ${ }^{56}$ : el análisis retórico ${ }^{57}$. Su principal cometido está en «el estudio de las múltiples formas de paralelismo y de otros procedimientos semíticos de la composición que deberían permitir discernir mejor la estructura literaria de los textos y llegar así a una mejor comprensión de su mensaje» ${ }^{58}$. Estas aproximaciones metodológicas, ciertamente, no son las únicas, pero sí se constituirían en las de mayor relevancia.

\subsubsection{Redescubrimiento de las dimensiones comunicativa y pragmática del texto bíblico}

Sería en este ambiente conciliar y postconciliar, que aparecerían las propuestas de Fritzleo Lentzen-Deis (1928-1993). Formado en el seno de los métodos histórico-críticos, fue testigo del florecimiento y consolidación de las nuevas perspectivas metodológicas de tipo sincrónico. En dicho contexto, seguramente se convencería que «ningún método científico para el estudio de la Biblia está en condiciones de corresponder a toda la riqueza de los textos bíblicos» ${ }^{59}$, pero cada uno de ellos es, indiscutiblemente, una puerta de acceso a sus inagotables tesoros. En este sentido, el biblista alemán procura una aproximación metodológica integrativa más que alternativa, que aprovecha lo más excelso de cada uno de los métodos, incluidos los histórico-críticos ${ }^{60}$, contribuye a superar los límites encontrados y, sobretodo, abre sus horizontes hacia el redescubrimiento y valoración de las dimensiones

\footnotetext{
${ }^{55}$ Es el resultado de un extenso «diálogo establecido, de manera constante e imprescindible entre los exégetas y teólogos de diversas confesiones cristianas con historiadores, sociólogos, lingüistas, críticos literarios, artistas, semiólogos, y filósofos, que ha redundado en un notable servicio para la comprensión del texto sagrado». Alfonso Rincón, «La Biblia en la encrucijada de múltiples lecturas», En A la luz y al servicio de la Palabra, homenaje al P. Pedro Ortiz Valdivieso, S.J., comp. José Alfredo Noratto (Bogotá: Facultad de Teología, PUJ, 2006), 46.

${ }^{56} \mathrm{Si}$ bien es cierto se trata de la cultura hebrea, manifestada prevalentemente en la lengua propia del A.T. No obstante, se debe reconocer que también abraza al N.T. pues viene escrito en griego sobre una mentalidad cuyas raíces profundas son hebreas. Véase Roland Meynet, Leggere la Bibbia, 67. 70.

57 Vale la pena aclarar que aquí se refiere específicamente a la retórica semítica, muy distinta de la retórica clásica que nace y se consolida en el ámbito greco-romano y cuyos principios metodológicos también vienen utilizados en el análisis de los textos bíblicos, sobretodo de los libros sapienciales y los escritos paulinos, pero que no se considera como un método moderno en cuanto que, de alguna manera, ha estado presente en el quehacer teológico de la Iglesia casi desde sus inicios. Véase Francesco Bianchini, L'Analisi Retorica delle Lettere Paoline (Milano: San Paolo, 2011), 5 ss.

${ }^{58}$ Pontificia Comisión Bíblica, La interpretación de la Biblia en la Iglesia, 41.

${ }^{59}$ Pontificia Comisión Bíblica, La interpretación de la Biblia en la Iglesia, 40.

60 Horacio Simian-Yofre, «Pragmalingüística: comunicación y exégesis», 95. Pese a que el análisis pragmalingüístico de la Escritura se sitúa más en el ámbito de la sincronía, no lo hace en oposición a la diacronía, sino abierto a ella, a la que continuamente acude para hallar sustento y complemento armónico. Cesar Mora Paz, «Los métodos de Análisis Literario: el método pragmalingüístico», 72-73; véase Ulrich Berges, «La lingüística pragmática como método de la exégesis bíblica», 70-71.
} 


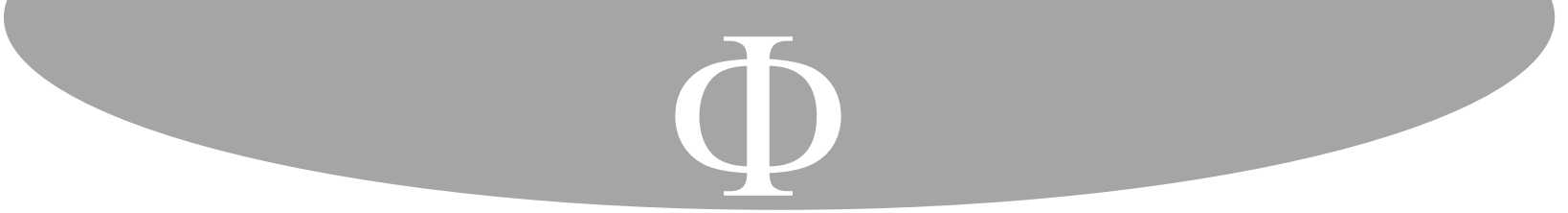

reconocida en el ámbito espiritual y pastoral, no siempre ocupa un puesto prioritario en el mundo de la exégesis, cuyo carácter ha sido más de orden teórico ${ }^{78}$.

Un tercer elemento, derivado de los anteriores, y de especial relevancia en la consolidación del método, está la prospectiva más dinámica con la que es percibida la relación intrínseca autor-texto-lector, y ésta con el mundo extralingüístico. De manera particular, el lector ha ganado protagonismo en la comprensión de la Escritura, ya que revaloriza el carácter comunicativo de la Palabra de Dios en el redescubrir su dimensión dialógica. En este sentido, el autor, el destinatario o lector, y junto a ellos el contexto en el que se hallan ${ }^{79}$ son de vital importancia.

El autor define la orientación del texto que produce y es quien, de alguna manera, diseña, imagina o proyecta la estrategia que pone en acto para comunicar el mensaje. Sin embargo, con él no se agota la riqueza del texto, el lector también lo enriquece, pues no es destinatario pasivo, sino un actor creativo capaz de descubrir elementos de los que quizá no fue consciente el autor, pero que están presentes en el texto. Debido a las circunstancias en las que este último se encuentre, puede hallar nuevos significados o nuevos matices, sin que se altere la originalidad o la dinámica del texto ${ }^{80}$; sino que más bien la completa y perfecciona. Lo mismo sucede con el contexto, que no se trata únicamente de circunstancias o parámetros espaciotemporales de una composición textual, sino que impregna profundamente su sentido, intención y alcance, logrando interpelar a los destinatarios/lectores originales y también a los de otros tiempos ${ }^{81}$.

Ahora bien, a pesar de las coincidencias con los demás métodos, en determinado momento, el análisis pragmalingüístico de la Escritura se aparta de ellos y adquiere su propia

\footnotetext{
${ }^{78}$ Fritzleo Lentzen-Deis, «La Ciencia de la exégesis y la hermenéutica pastoral», en Jesús en la reflexión exegética y comunitaria. La exégesis y la lectura de la Biblia en grupos, ed. Fritzleo Lentzen-Deis, Gert Scobel, Cesar Mora Paz y Pierre Deberge (Bogotá: Ediciones Paulinas, 1990), 14. En este sentido, la pragmática se constituye en un puente que cierra la brecha existente entre exégesis científica y pastoral. Ulrich Berges, «La lingüística pragmática como método de la exégesis bíblica», 88 y 90; Fritzleo Lentzen-Deis, Cesar Mora Paz, Michael Sievernich y Hans Joachim Höhn. Avances metodológicos de la exégesis para la praxis de hoy, 7. «Una vez establecido el contenido, la intencionalidad y el efecto de un texto bíblico, el teólogo tiene pautas más seguras para la aplicación y la actualización del mismo». Ulrich Berges, «Lectura pragmática del Pentateuco: Babel o el fin de la comunicación», 73. «La regla directiva de esta ciencia es la siguiente: establecer la correlación entre el modelo de acción expresado en el texto y las exigencias del oyente-interlocutor de hoy», Fritzleo Lentzen-Deis, «La Ciencia de la exégesis y la hermenéutica pastoral», 21.

79 Véase Massimo Grilli, «Interpretazione e azione», 14.21-22; Horacio Simian-Yofre, «Pragmalingüística: comunicación y exégesis», 91-92; Berges, «La lingüística pragmática como método de la exégesis bíblica», 64.67.75.83.

${ }^{80}$ Massimo Grilli, «Interpretazione e azione», 35; Horacio Simian-Yofre, «Pragmalingüística: comunicación y exégesis», 91-92. «Cuando... el autor entra en su propia muerte, la escritura comienza», Roland Barthes, «La mort de l'auteur», en Le bruissement de la langue, Essais critiques IV (Paris: Seuil, 1984), 61, esta era una afirmación que en 1968 parecía exagerada, pero que, gracias a los avances de los estudios lingüísticos y, sobre todo, en el orden pragmático, daría un gran impulso al reconocimiento del papel protagónico que cumple el lector.

${ }^{81}$ Ulrich Berges, «La lingüística pragmática como método de la exégesis bíblica», 83.
} 


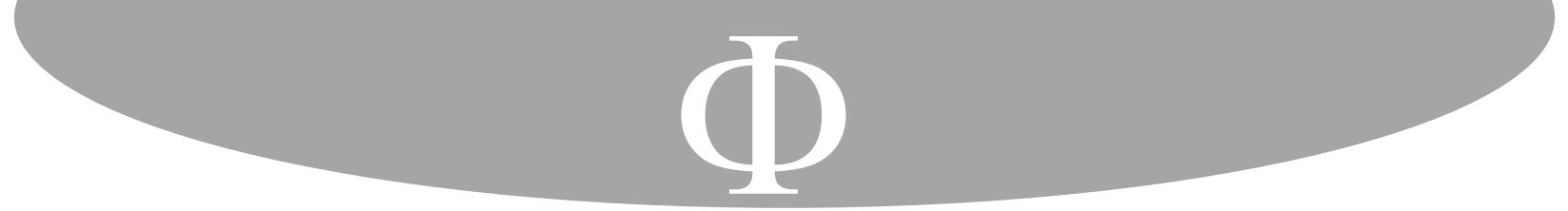

dan su particular finalidad, los cuales caben bajo el denominativo ya dado de contexto. Así pues, la atención de este apartado se centra en la influencia que este ejerce sobre el texto. Para ello, en un primer momento, se brindarán algunas precisiones conceptuales básicas para luego evidenciar los elementos fundamentales que son determinantes en su configuración.

\subsubsection{Texto, co-texto y contexto}

El punto de partida y concepto fundamental es el de texto. Este hace referencia a «tejido», por su etimología del latín textus, participio pasado del verbo texere que significa tejer. En este sentido, el texto se define como una red de relaciones lingüísticas, o más técnicamente como una unidad lingüística estructurada y armónica (tejido) en orden a la comunicación ${ }^{87}$.

Así pues, pese a que, en la práctica común, el texto se refiera a contenidos lingüísticos escritos, más bien, corresponde a comunicaciones escritas y orales, con sus referidas particularidades ${ }^{88}$. Para el presente artículo, la comprensión de texto estará limitada a la comunicación escrita, ya que el acceso a las fuentes bíblicas solo se alcanza mediante los textos escritos con los que hoy se cuenta ${ }^{89}$; no obstante, se ha de tener presente que sus estadios primigenios fueron tradiciones orales.

Ahora bien, para que un texto sea una unidad estructurada y armónica necesita una «extensión precisa», con «cohesión»y «coherencia»; y, para que sea en orden a la comunicación, requiere una cierta «intención comunicativa» que da el autor a través de una «estrategia narrativa» ${ }^{90}$.

Por ahora, se precisan sus características esenciales:

- Extensión: hace referencia a una porción textual delimitada, gracias a ciertos indicios lingüísticos, de tipo formal o temático, que le constituyen en una estructura comunicativa compleja pero unitaria ${ }^{91}$.

\footnotetext{
${ }^{87}$ Massimo Grilli, «Interpretazione e azione», 30.

${ }^{88} \mathrm{Si}$ bien, se afirma que la distinción entre lenguaje oral y escrito es solo de forma (dos formas del mismo lenguaje), Michael Halliday, Lingua parlata e lingua scritta (Firenze: La Nuova Italia, 1992), 180, es preciso indicar que hay distinciones precisas entre ellas. Mientras «el texto oral es un texto vivo, fragmentado, con enunciados sobre todo breves y sujetos a continuos ajustes de formulaciones, de explicitaciones, repeticiones, etc., el texto escrito es estratificado, permanente, conciso y al mismo tiempo dotado de una mayor complejidad lexical y sintáctica. (...) En una comunicación verbal de tipo oral, el tono de la voz, las expresiones del rostro, los gestos, son indicios que ayudan a comprender la función de un determinado texto, mientras en un texto escrito el proceso se presenta más articulado y ciertamente laborioso». Massimo Grilli, «Interpretazione e azione», 33-34; véase Maurizio Guidi, «La questione contestuale», 61-62 y Horacio Simian-Yofre, «Pragmalingüística: comunicación y exégesis», 89.

${ }^{89}$ «El objeto inmediato de la ciencia veterotestamentaria son textos. Por ser textos, exigen del exégeta una reflexión sobre el lenguaje, la realidad específica de textos, la relación de autor, lector, texto y mundo extralingüístico». Ulrich Berges, «Lectura pragmática del Pentateuco: Babel o el fin de la comunicación», 64.

${ }^{90}$ Massimo Grilli, «Interpretazione e azione», 30.

${ }^{91}$ Massimo Grilli, «Consideraciones en torno a la sintáctica», En Lectura pragmalingüística de la Biblia. Teoría y aplicación, 35 .
} 


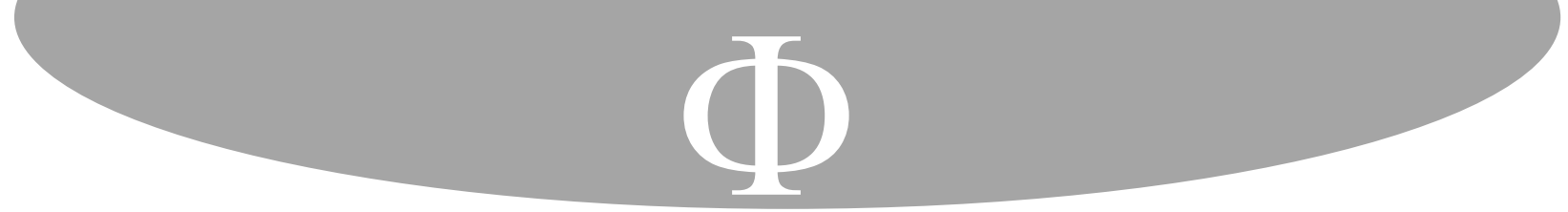

- Cohesión: conexión entre las partes de un texto, evidenciadas por diversos dispositivos de orden lexical y gramatical, que puede incluir indicaciones de tipo morfológico, pero sobretodo, sintáctico ${ }^{92}$.

- Coherencia: está relacionada con «la organización semántica interna, que (...) gira en torno a las propiedades de la continuidad y la jerarquía, diversamente declinadas» ${ }^{93}$. Si bien es cierto, se soporta en el esquema lexical y gramatical que está a la base de la construcción del texto, va más allá y alcanza «los contenidos de los enunciados que componen el texto, con la articulación y el desarrollo de los motivos que contribuyen a constituir el mensaje unitario o tema» ${ }^{94}$.

El segundo gran concepto es el de co-texto, acuñado particularmente para hacer referencia al contexto literario de un texto, pues corresponde al conjunto de unidades textuales con las que constituye una unidad superior y se sitúa dentro de la obra literaria ${ }^{95}$. Corresponde a una categoría de orden sintáctico y se desprende del concepto de texto, que posee una extensión precisa, con lo que se subraya la existencia de unos límites que se relacionan por su continuidad, distinción o contraste, para una mejor comprensión ${ }^{96}$. Este $c o-$ texto se diferencia del contexto comunicativo o situacional ${ }^{97}$.

$\mathrm{Al}$ respecto, el co-texto amplio o co-texto remoto hace referencia a la obra entera o a una parte de esta, con la que por obvias razones el texto de estudio entra en relación; mientras, el co-texto próximo o inmediato corresponde a las unidades textuales cercanas con las que se da un tipo de conexión estrecha y considera diversos elementos formales, sintácticos, semánticos, retóricos y narrativos cuya incidencia en el texto va sopesada cuidadosamente. En el caso de los relatos bíblicos, los criterios narrativos son prioritarios: cambios de lugar, de tiempo, de protagonistas y escenas, ligados a otros indicios de orden sintáctico y retóricoformal $^{98}$.

\footnotetext{
92 Massimo Grilli, «Interpretazione e azione», 31-32; Elzbieta M. Obara, Le strategie di Dio. Dinamiche comunicative nei discorsi divini del Trito-Isaia (Roma: Gregorian \& Biblical Press, 2010), 26. Muchas palabras desconectadas y a la deriva no constituyen un texto. Los dispositivos cohesivos clásicos y comunes son las repeticiones lexicales, los pronombres, los conectivos coordinantes y subordinantes como: no obstante, así, en efecto, entre otros: Massimo Grilli, «Interpretazione e azione», 32.

${ }^{93}$ Angela Ferrari, Linguistica del testo. Principi, fenomeni, strutture (Roma: Carocci, 2014), 115; véase Elzbieta M. Obara, Le strategie di Dio, 26-28.

${ }^{94}$ Massimo Grilli, «Interpretazione e azione», 31-32. Cuando se habla de «motivo» se refiere a la unidad mínima de significado, por cuya interconexión con otros de la misma línea permiten evidenciar el tema de fondo del conjunto de un texto. Para una visión más amplia al respecto, véase Elzbieta M. Obara, Le strategie di Dio, 2325.

${ }^{95}$ Massimo Grilli, «Parola di Dio e linguaggio umano», 533; véase Roland Meynet, Leggere la Bibbia, 136137.

96 Ver Maurizio Guidi, «La questione contestuale», 65.

97 Guidi atribuye a Petöfi la distinción entre co-texto y contexto, sucesivamente recibida en el ámbito pragmático. Maurizio Guidi, «La questione contestuale», 59.

${ }^{98}$ Maurizio Guidi, «La questione contestuale», 59.
} 


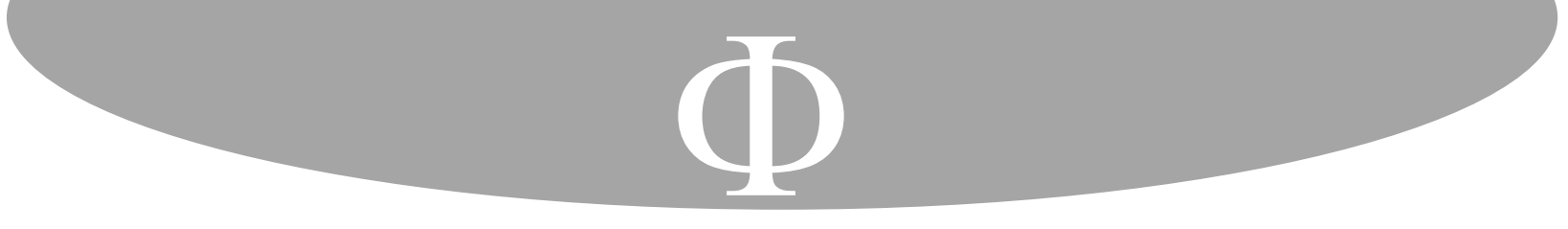

que separa su constitución con sus lectores es muy amplia e indeterminada, como en el caso de numerosas obras clásicas y los escritos bíblicos ${ }^{106}$.

Desde dichas circunstancias, la reconstrucción de los contextos puede darse mediante el acceso a fuentes históricas, culturales o literarias externas «próximas»; sin embargo, esta es una vía incierta, para los datos que puedan ser extractados de la fuente más segura que se posee: el texto mismo. Con todo ello, es necesario hacer un cuidadoso estudio textual, que permita identificar el influjo del contexto sobre el texto, ya sea por expresiones indicativas de persona, lugar o tiempo; por ambigüedades en el uso del lenguaje, que empiezan a aclararse cuando se conocen detalles de contextos particulares, en algunas ocasiones, gracias a la confrontación con las fuentes externas antes indicadas; o por ciertos tipos de lenguaje que se puedan evidenciar ${ }^{107}$.

En síntesis, se trata de elementos presentes como trasfondo, que en ocasiones son vistos sin mayor valoración dentro de la comunicación, pero que hacen posible cambiar el valor semántico de un enunciado y que, en su conjunto, bien podrían denominarse «expresiones contextuales» ${ }^{108}$. Así, la tarea del intérprete, o del exégeta en el caso particular de los escritos bíblicos, implica configurar los elementos constitutivos y las dinámicas relacionales de la influencia del contexto sobre el evento comunicativo, y, en lo específico, sobre aquella particular forma de comunicación que se realiza en un determinado texto ${ }^{109}$.

Por último, es necesario presentar una precisión final que es fundamental para el análisis pragmalingüístico, a saber: el texto no solo tiene la capacidad de reenviar a un contexto original posible, también tiene la plasticidad para recibir la influencia de nuevos contextos y ser enriquecido en las intenciones puestas de manifiesto por el autor. Es decir, texto y contexto interactúan continuamente entre sí, de otra manera, se podría decir que el contexto mantiene un peculiar carácter dinámico, permitiendo la continua recontextualización y actualización de un texto y su variedad interpretativa ${ }^{110}$.

\footnotetext{
106 Massimo Grilli, «Interpretazione e azione», 34; Maurizio Guidi, «La questione contestuale», 61-62. La constitución indeterminada de los escritos bíblicos corresponde particularmente a los escritos veterotestamentarios.

107 Maurizio Guidi, «La questione contestuale», 52 y 55.

108 Maurizio Guidi, «La questione contestuale», 53 y 55.

${ }^{109}$ Maurizio Guidi, «La questione contestuale», 58. Para una mayor profundización, se puede acudir a la primera parte de Maurizio Guidi, «Così avvenne la generazione di Gesù Messia». Paradigma comunicativo e questione contestuale nella lettura pragmatica di Mt 1,18-25 (Roma: Gregorian \& Biblical Press, 2012), 38-136, o a algunas publicaciones de Claudia Bianchi, «Context off Utterance and Intended context», en Modeling and Using Context. Third International and Interdisciplinary Conference, Context 2001, ed., Varol Akman, Paolo Bouquet, Richmon Thomason y Roger A. Young (Berlin Heidelberg: Springer-Verlag, 2001) y La dipendenza contestuale. Per una teoria pragmatica del significato (Napoli: Edizioni Scientifiche Italiane, 2001).

${ }^{110}$ Maurizio Guidi, «La questione contestuale», 62. Basta insistir que con esto no se están abriendo las puertas a una libre interpretación de la Escritura, pues la alianza comunicativa que se establece entre autor y lector está mediada por la armónica y equilibrada cooperación entre los elementos textuales plasmados por el autor (sintaxis, semántica, géneros literarios, ambigüedades, entre otros) y las inferencias del lector cuando se hace preguntas y se plantea hipótesis. Dicho de otro modo, para evitar que la reconstrucción del contexto y el sentido
} 


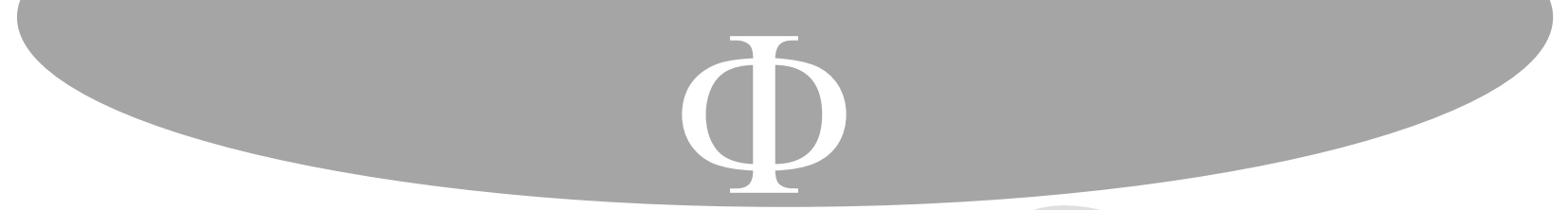

\subsubsection{La intención comunicativa: lector modelo y estrategia narrativa}

Determinar una serie de elementos que le dan cohesión sintáctica y coherencia semántica al texto, permiten vislumbrar el contexto en el que pudo surgir. Sin embargo, esta búsqueda adquiere sentido cuando se alcanza una mayor y mejor comprensión de la intención comunicativa ${ }^{111}$ con la que su autor quiso construir su texto y para la que se puso en marcha todo el andamiaje literario que le ha dado vida en el modo como hoy existe ${ }^{112}$. Y todo este esfuerzo, que vale la pena realizar para obtener un acercamiento, lo más próximo posible, a obras de gran valor cultural y literario, surgidas a lo largo de la historia, adquiere mayor significado cuando se trata de la Escritura, que además de los méritos indicados, desde una lectura creyente va más allá, en cuanto que representa la Palabra viva y eficaz, que ayuda a vivir el presente, a evaluar el pasado y a proyectar el futuro ${ }^{113}$.

Ahora bien, en la búsqueda de dicha intención comunicativa de un texto, es imprescindible tomar algunos elementos presentes en las composiciones literarias, y cuya relevancia se da gracias a la reciente perspectiva pragmática de las ciencias lingüísticas. Se trata del lector modelo y la estrategia narrativa o textual ${ }^{114}$.

Respecto al primero, el lector modelo, uno de los autores que contribuyó a su reflexión fue el semiótico italiano Umberto Eco ${ }^{115}$. Para él, se trataba de «un conjunto de condiciones, (...) establecidas textualmente, que deben satisfacerse para que el contenido potencial de un

del texto responda simplemente a la capacidad creativa del lector, este debe respetar los factores textuales que configuran su estructura, Maurizio Guidi, «La questione contestuale», 63.

111 «La intención del texto se podría definir, tentativamente, como la capacidad de acción o influjo que un determinado texto tiene en determinadas circunstancias», Horacio Simian-Yofre, «Pragmalingüística: comunicación y exégesis», 85 .

112 Véase Massimo Grilli, «Interpretazione e azione», 30; Elzbieta M. Obara, «Le azioni linguistiche», 111-112.

${ }_{113}$ Massimo Grilli, «Interpretazione e azione», 44.

${ }^{114}$ En algunos ambientes literarios, se habla de autor modelo, por utilizar una categoría análoga a la del lector modelo. Véase Umberto Eco, Seis paseos por los bosques narrativos (Barcelona: Lumen, 1996), 16-33; Lector in fabula. La cooperación interpretativa en el texto narrativo (Barcelona: Lumen, 1981), 89-95. Sin embargo, en el ámbito del análisis pragmalingüístico de la Sagrada Escritura no se la da la misma relevancia, porque el interés del método no es el autor. El razonamiento en el que se funda la necesidad de acudir a la figura «parametral» del lector modelo y no tanto del autor modelo: es en cuanto que el autor sagrado es el autor histórico y no hay otro, aunque sea desconocido, pero no se puede afirmar lo mismo del lector, quien sí es cambiante. Por lo tanto, resulta útil establecer un perfil estándar con el que todos se puedan confrontar. Cf. Horacio Simian-Yofre, «Pragmalingüística: comunicación y exégesis», 78.

$115 \mathrm{Su}$ mayor contribución, en el último cuarto del siglo anterior, fue Lector in fabula e I limiti dell'interpretazione (Los límites de la interpretación). En estas publicaciones sigue de cerca lo propuesto por el alemán Wolfgang Iser, en Der implizite Leser, quien había insinuado el concepto de «lector implícito» como estrategia textual. Massimo Grilli, «Interpretazione e azione», 36. Iser lo define como «la peculiaridad del acto de leer, delineada en el texto», Iser, Der implizite Leser (UTB 163, 1979), 8-9, citado por Rainer Dillmann, «Consideraciones en torno a la pragmática», en Lectura pragmalingüística de la Biblia. Teoría y aplicación, 68. 


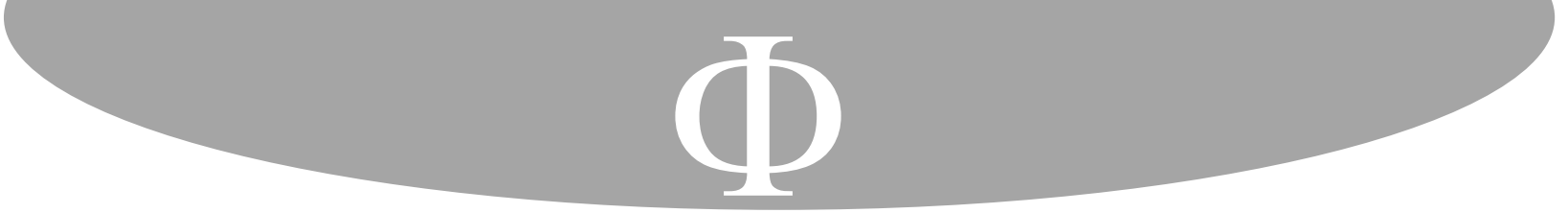

temerarios. A través del lector modelo un texto pone sus reglas de juego, que un lector empírico puede aceptar o no. No obstante, el éxito (...) se da cuando el lector empírico se ajusta a las reglas de juego, de este juego interpretativo» ${ }^{122}$. Para ser precisos, se debe decir que el lector se convierte en garante de la verdad del texto puesto que el lector empírico, al confrontarse con él, comprende que no puede hacer con el texto aquello que se le antoje ${ }^{123}$.

Ahora bien, no obstante en los procesos interpretativos es necesario dedicar un interés particular por el lector modelo inscrito en el texto al momento de su composición, no podemos anclarnos allí, sino que tenemos que ir en búsqueda de los efectos que el texto inspirado produce en los receptores de cada momento ${ }^{124}$. Por ello, el texto no puede ser considerado como un objeto finito, definido e inmutable, sino en continuo progreso y en continua relación con su lector ${ }^{125}$. En este sentido, aparece un elemento trascendental a tener en cuenta: la distancia que existe entre la constitución del texto y su lectura, en niveles diversos como el lingüístico, social, cultural, temporal, contextual, entre otros. En otras palabras, no se puede olvidar que por más cercano que parezca, se trata de un texto nacido en un contexto diferente al del lector ${ }^{126}$.

Frente esta realidad, surge la pregunta: ¿de qué manera el lector actual puede superar la distancia que lo separa de la constitución original del texto y entrar en una eficaz comunicación de este, sin hacer una ciega actualización y apropiación, ni reducir la interpretación a la fría contemplación de un objeto que no le pertenece ${ }^{127}$. En términos de Grilli:

¿de qué modo podemos superar la distancia entre nosotros y el texto, sin manipularlo, pero también sin reducirlo a un pedazo de anticuario para contemplar? (...) ¿Cómo podemos nosotros (...) medirnos en una correcta relación con el texto bíblico, de modo que el venir del texto hacia mí y el andar mío hacia el texto (...), sea un camino respetuoso y al mismo tiempo apasionante? ${ }^{128}$.

\footnotetext{
${ }^{122}$ Massimo Grilli, «Interpretazione e azione», 38; véase Umberto Eco, Seis paseos por los bosques narrativos, 32-33.

${ }^{123}$ Grilli, «Interpretazione e azione», 43. «Delante de un texto el lector empírico puede hacer todas las conjeturas posibles, pero al final estas deben ser probadas sobre la base de la coherencia de la obra, o en términos pragmáticos, sobre la base de aquel tejido textual que se llama lector modelo». Grilli, «Interpretazione e azione», 43; véase Rainer Dillmann, «Consideraciones en torno a la pragmática», 73.

${ }^{124}$ Christoph Theobald, "Seguendo le orme...» della Dei Verbum. Bibbia, teologia e pratiche di lettura (Bologna: Edizioni Dehoniane Bologna, 2011), 71.

125 Massimo Grilli, «Interpretazione e azione», 42; Debora Tonelli, Imagini di violenza divina nell'Antico Testamento (Bologna: Edizioni Dehoniane Bologna, 2014), 21. De hecho, «el efecto que tenía previsto el autor puede ciertamente ser conseguido hoy, pero no necesariamente lo es», Rainer Dillmann, «Consideraciones en torno a la pragmática», 66.

126 Rainer Dillmann, «Consideraciones en torno a la pragmática», 60; Massimo Grilli, «Interpretazione e azione», 44.

127 Véase Rainer Dillmann, «Consideraciones en torno a la pragmática», 61.

${ }^{128}$ Massimo Grilli, «Interpretazione e azione», 45.
} 


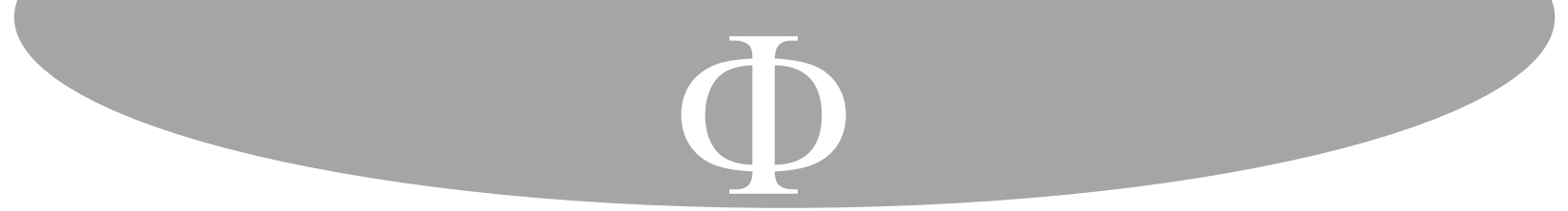

En este sentido, Grilli aporta otra función del lector modelo: la actualización del texto, pues pone en diálogo al lector de todos los tiempos con la verdad que reposa en el texto, ofreciéndole una exigencia de traducirla en modalidades concretas de existencia:

De frente a él, que combina en si las cualidades ideales de un lector, el lector empírico es forzado a una relación constante y verdadera, participando de las emociones provocadas por el texto y sobretodo, aprendiendo a acoger el sistema de valores allí contenidos. Los lectores de cada tiempo, de diversa cultura, clase social y sensibilidad, entre otros, son llamados constantemente a interactuar con este lector implícito delineado en el texto y a configurarse según aquellos modelos por él encarnados; no simplemente copiándole, sino repensándole, reinterpretándole. Es del todo evidente que, de este modo, la verdad representada por el lector modelo no se agotará en una única actuación, sino que asumirá modalidades diversas, según las circunstancias o modalidades contenidas, siempre, en la verdad del único lector modelo. De este modo la exégesis bíblica recupera su dimensión hermenéutica y se convierte en fuente de vida para el actuar de los individuos y de las comunidades ${ }^{129}$.

Ahora bien, si el lector modelo es, en la mente del autor, el parámetro o referente ideal, sobre el que tiene una o varias intenciones precisas al momento de componer el texto; la estrategia narrativa o textual se considera el vehículo de concreción de su «intención comunicativa», conforme a las exigencias, reales o imaginadas, de aquel ${ }^{130}$.

Se trata de dos elementos ligados intrínsecamente, entre los cuales es posible percibir una relación de doble vía, en cuanto que, para responder a las características o al perfil del lector modelo, el autor construye una determinada estrategia narrativa, y a la vez, es a través de dicha estrategia plasmada en el texto que, no obstante las distancias, se consigue vislumbrar el perfil del lector modelo ${ }^{131}$.

La estrategia narrativa utilizada por el autor consiste entonces en la manera particular como es configurado todo el conjunto de elementos hasta aquí mencionados, lexicales, gramaticales, retóricos y semánticos del texto, que le dan la cohesión y coherencia propias, en específica relación con el co-texto y el contexto. Ciertamente, no equivale de modo exacto ni exclusivo a la estructura textual o esquema narrativo, aunque ésta sí representa el soporte

\footnotetext{
${ }^{129}$ Massimo Grilli, «Interpretazione e azione», 46.

${ }^{130}$ Véase Fritzleo Lentzen-Deis, «El relato de la pasión, ¿un modelo de acción?», 19.

${ }^{131}$ Es a través de la estrategia narrativa -que presupone un lector modelo-que el autor real y el lector real entran en diálogo. Massimo Grilli, «Parola di Dio e linguaggio umano», 532.
} 


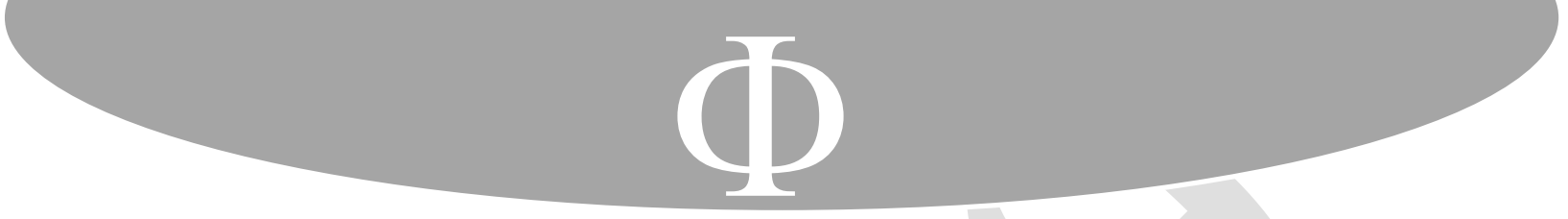

fundamental de aquella ${ }^{132}$, cuya columna vertebral es el sistema verbal utilizado por el autor. Por ello, su centralidad resulta indiscutible ${ }^{133}$ y merece una atención particular.

Sobre el núcleo que constituye el entramado verbal, en el ámbito del análisis pragmalinguiístico de la Escritura, la propuesta de Niccacci se presenta como oportuna. Fundada en algunas intuiciones basilares de Harald Weinrich ${ }^{134}$, sobre los distintos niveles del texto desde tres puntos de vista: la actitud lingüística (narrar / comentar), la perspectiva lingüística (información recuperada / grado cero / información anticipada) y la puesta de relieve (primer plano, fondo $)^{135}$, ofrece una comprensión amplia y detallada, que aplicada al hebreo resulta compleja, en cuanto que posee un numero considerablemente menor de formas verbales, que las lenguas modernas ${ }^{136}$. Por lo tanto, sin abandonar los demás aspectos, Niccacci centró su atención en la puesta de relieve, que consiste en la identificación de tres niveles básicos del texto bíblico: primer plano, fondo y discurso directo ${ }^{137}$.

Este último, el discurso directo, no reviste mayor complejidad y su identificación resulta evidente ya que se trata de las voces directas de los personajes. Pertenece al fondo o al primer plano, de acuerdo con las construcciones verbales que lo introducen ${ }^{138}$.

\footnotetext{
132 Efectivamente se debe tener presente que «el sentido de un texto literario depende en buena parte de su configuración lingüística». Robert Alter, The art of Biblical Narrative (New York: Basic Books, 1981) x; y con mayor razón «en el caso de la Biblia, la forma es parte del contenido y por tanto la comprensión de su mensaje implica en gran manera aquella de la modalidad expresiva», Debora Tonelli, Imagini di violenza divina nell'Antico Testamento, 20. En cuanto, a su implicación pragmática, Lentzen-Deis es explícito cuando afirma que «la estructura textual relatada debe describirse como un medio para suscitar la acción en el receptor». Fritzleo Lentzen-Deis, «El relato de la pasión, ¿un modelo de acción?», 19.

133 Massimo Grilli, «Interpretazione e azione», 32; De otro modo, se hablará del «verbo como motor del desarrollo narrativo», Maurizio Guidi, «La questione contestuale», 67. Las estructuras verbales tienen un peso notable para la interpretación literaria, aunque unidas a las demás marcas dan el relieve narrativo, Maurizio Guidi, «La questione contestuale», 68.

134 Weinrich comprende los signos lingüísticos, particularmente los verbos, como instrucciones, pues el hablante comunica sus propias intenciones comunicativas al interior de un determinado juego lingüístico; contando con la distinción entre tiempos comentativos y tiempos narrativos (tiempos semifinitos y tiempos finitos), donde procederá la división entre fondo y primer plano. Maurizio Guidi, «La questione contestuale», 59; Jean-Louis Ska, «Sincronía», 154-156.

135 Véase Harald Weinrich, Estructura y función de los tiempos en el lenguaje (Madrid: Gredos, 1968) 51-81.

${ }^{136}$ Alviero Niccacci, Sintaxis del Hebreo Bíblico (Estella: Verbo Divino, 2002), 103. Un elemento fundamental en la propuesta de Weinrich es el análisis de las transiciones de un nivel a otro, Alviero Niccacci, Sintaxis del Hebreo Bíblico, 104.

${ }^{137}$ Alviero Niccacci, Sintaxis del Hebreo Bíblico, 181. Mientras que Weinrich hace su propuesta en el contexto del análisis de las lenguas modernas occidentales, Niccacci, de manera amplia y detallada, hace una observación comparada de las lenguas latinas modernas con la estructura sintáctica del hebreo bíblico, basado en el manejo verbal, en su libro Sintassi del verbo ebraico nella prosa bíblica classica -1986, y de manera comparada con el griego bíblico, en su artículo «Dall'aoristo all'imperfetto o dal primo piano allo sfondo. Un paragone tra sintassi greca e sintassi ebraica», Studii Biblici Franciscani Liber Annus -SBFLA 42 (1992): 85-108. Su propuesta será acogida de manera positiva en el ámbito del análisis narrativo, y en el seno del análisis pragmalingüístico, en modo particular por Massimo Grilli y Maurizio Guidi.

138 Maurizio Guidi, «La questione contestuale», 72.
} 


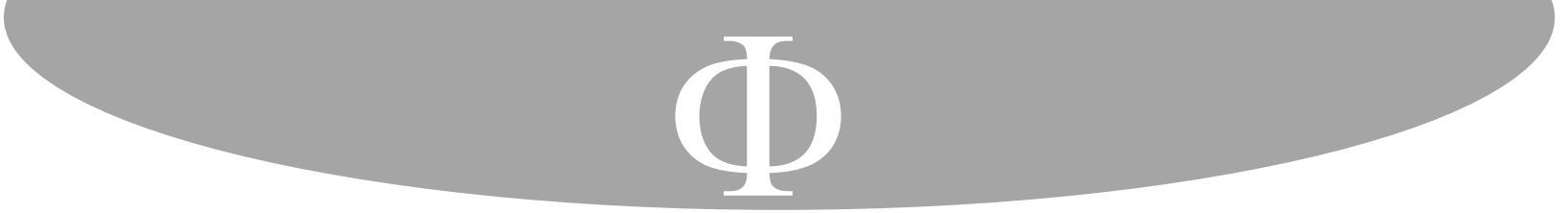

Por su parte, el primer plano y el fondo dan relieve al relato, pues lo articulan mediante las formas verbales particulares, que para su mejor comprensión son asociadas a las formas propias del español, gracias a las respectivas equivalencias del griego y hebreo bíblico. Así, se puede afirmar que, en la narración, el "pretérito perfecto simple o pasado simple» (correspondiente en griego al «indicativo aoristo» y en hebreo a la forma «wayyiqtol») es el tiempo del primer plano ${ }^{139}$, mientras que el «pretérito imperfecto» (correspondiente en griego también al «imperfecto», y en el hebreo a la forma «waw-X-qatal») es el tiempo del fondo ${ }^{140}$.

Esta configuración esquemática de los tres niveles ayuda a comprender dónde está el peso del relato y da pistas para la valorización que debe darse a cada parte en el proceso de búsqueda del sentido del conjunto y de su intención comunicativa ${ }^{141}$. Sin embargo, se debe aclarar que no solo se debe identificar la fuerza de cada uno de los niveles, sino la dinámica de transición de un tiempo al otro. Esta dinámica que se presenta en las lenguas latinas modernas también aparece en el griego y el hebreo bíblicos (el movimiento del primer plano al fondo viene marcado en el griego por el paso del aoristo al imperfecto y en el hebreo por la secuencia wayyiqtol / waw-x-qatal, denotando una dependencia lingüístico-textual del segundo frente al primero), ayudando enormemente al intérprete a detectar la estrategia narrativa sugerida en el texto ${ }^{142}$.

Finalmente se ha de decir que, si bien es cierto la estrategia narrativa expresa la concreción definitiva de la influencia que ejerce el contexto sobre el texto, y por eso aparece al cierre de este apartado, también es igualmente valido indicar que ésta, no solo responde a una serie de condiciones que pudieron influir sobre el texto al momento de su constitución, sino que también viene diseñada en un modo tal que sea capaz de generar algún tipo de efecto sobre los destinatarios y su contexto particular. Efectivamente, sobre el modo como se realiza este último aspecto se tratará en el apartado que viene a continuación.

\footnotetext{
${ }^{139} \mathrm{Al}$ primer plano, o también denominado focalización narrativa, pertenece todo aquello por lo que se cuenta la historia, las acciones principales que hacen avanzar un relato dándole el ritmo propio, y si bien es cierto son acciones que generalmente vienen expresadas mediante el pretérito perfecto (en hebreo la forma «wayyiqtol»), también incluyen el presente histórico (uso del presente para narrar cosas pasadas). Ahora bien, además de los signos gramaticales que ayudan a determinar el primer plano, también contribuyen los géneros literarios o las formas retoricas (quizá un paralelismo estructural) que acompañan y especifican la función comunicativa del verbo, Maurizio Guidi, «La questione contestuale», 71-72. Valga la pena insistir que «entran en el primer plano, solo y tan solo las acciones esenciales sin las cuales la narración se convertiría en incoherente en su sucesión lógico-cronológica», Maurizio Guidi, «La questione contestuale», 72.

${ }^{140}$ Maurizio Guidi, «La questione contestuale», 68. El fondo se construye principalmente con el imperfecto, pero también con el pretérito pluscuamperfecto y el participio, con proposiciones secundarias o nominales, $\mathrm{u}$ otros elementos secundarios (títulos, sumarios, analepsis, prolepsis, o un comentario del narrador) que también hacen parte de este ámbito comunicativo. Elementos tales que al entretejerse con el primer plano dan origen a la trama narrativa, es decir al relato como viene expuesto en el texto, Maurizio Guidi, «La questione contestuale», 70 .

${ }^{141}$ Maurizio Guidi, «La questione contestuale», 72.

142 Maurizio Guidi, «La questione contestuale», 68-69; Alviero Niccacci, «Dall'aoristo all’imperfetto», 107108.
} 


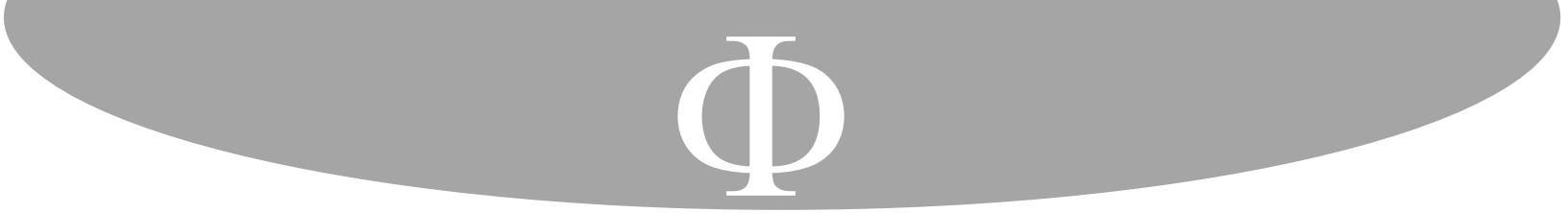

\subsection{La influencia del texto sobre el contexto}

$\mathrm{Si}$ una de las principales competencias de la pragmática es identificar el contenido proposicional de un texto en tanto es producto de una situación comunicativa específica, la otra tarea consiste en indagar sobre la influencia que el contenido proposicional ejerce en el contexto donde se lee: «la capacidad de un determinado enunciado de modificar el estado de las cosas y la situación del discurso, por ejemplo de influenciar el potencial cognitivo de los interlocutores, de cambiar, reforzar o eliminar determinadas creencias, convicciones, de condicionar sus deseos, su conocimientos o sus acciones» ${ }^{143}$. Sobre esto versará el presente apartado.

\subsubsection{La fuerza pragmática y la teoría de los actos lingüísticos}

La fuerza pragmática, que el lenguaje posee por naturaleza y que se consolida como uno de los hallazgos más significativos de la pragmalingüística, se constituye en el punto de partida para la consideración de la influencia del texto sobre el contexto. Esto se sustenta particularmente en los planteamientos de Austin, referidos previamente, con los que pone en evidencia que «todos los enunciados, más allá de contener un significado, cumplen una función de verdaderas y propias acciones, dada la presencia del elemento performativo en todo uso del lenguaje» ${ }^{144}$.

Así, cada enunciado deja de limitarse a ser tal, para convertirse en un acto lingüístico. Sobre esta intuición, se configura, finalmente, la llamada teoría de los actos lingüísticos, con la que Austin hace notar la presencia de tres sentidos o dimensiones en cada acto lingüístico ${ }^{145}$ :

- El acto locutivo: decir algo. Corresponde al hecho de proferir un enunciado y comprender los elementos puramente lingüísticos, gramaticales y lexicales, con su respectivo significado.

- El acto ilocutivo: acto que se cumple en el decir algo. Indica la acción que el emitente ejercita sobre el destinatario al momento de proferir un enunciado, su fuerza. Las formas expresivas de este aspecto "ilocutivo" dependen de los verbos y del contexto donde se pronuncien $^{146}$.

- El acto perlocutivo: es el acto que se cumple con el decir algo. Representa los efectos o las consecuencias que las acciones del emitente cumplen sobre el destinatario, aunque no son siempre previsibles ${ }^{147}$.

\footnotetext{
${ }^{143}$ Elzbieta M. Obara, «Le azioni linguistiche», 85.

${ }^{144}$ Elzbieta M. Obara, «Le azioni linguistiche», 95.

145 John L. Austin, Cómo hacer cosas con palabras, 141-149, 155 y 167; Massimo Grilli, «Parola di Dio e linguaggio umano», 529-530; Elzbieta M. Obara, «Le azioni linguistiche», 95-96.

146 «Entender el significado de un enunciado (...) significa comprender cómo un enunciado viene empleado en un particular contexto de acciones y palabras». Filippo Domaneschi, Introduzione alla pragmatica, 209.

147 «Hay que catalogar los textos como actos perlocutivos si dichos textos realmente realizan lo que pretenden», Rainer Dillmann, «Consideraciones en torno a la pragmática», 67.
} 


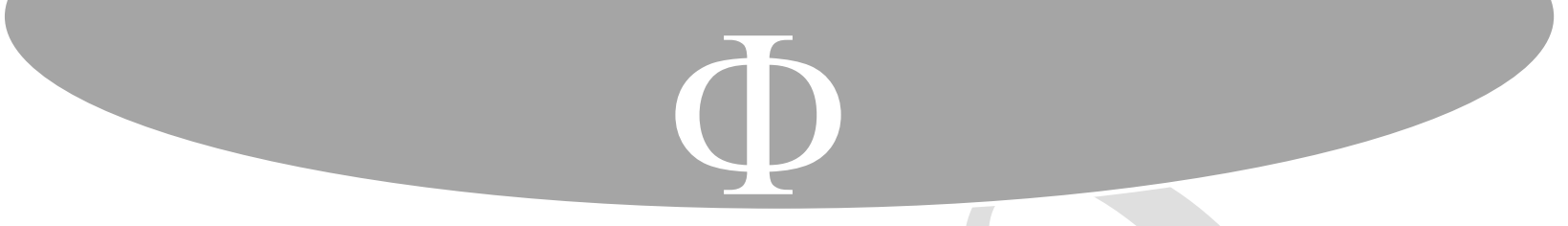

\subsubsection{Los actos ilocutivos y su clasificación}

En los términos descritos, es notorio reconocer que la primera dimensión no añade nada a los estudios lingüísticos tradicionales; más bien, reafirma la solidez de su interés por la parte lexical, gramatical y semántica. Respecto a la tercera, resulta ser un campo amplio y ambiguo, pues medir los efectos reales de los enunciados proferidos es complejo e incierto ${ }^{148}$. Sin embargo, la novedad de la teoría y su aplicabilidad a la comprensión de los textos bíblicos va más allá de proponer dicha tripleta, su interés está en la segunda dimensión, sobre la que Austin hizo un primer intento de caracterización de los actos de acuerdo con su fuerza ilocutiva $^{149}$, que solo alcanzó hasta la clasificación de los verbos ${ }^{150}$.

Así pues, Searle, continuando con el propósito de Austin y enfocado en la fuerza ilocutiva de los actos lingüísticos ${ }^{151}$, identificó cinco categorías en las que se pueden agrupar para ser fácilmente reconocibles ${ }^{152}$. En los siguientes párrafos ${ }^{153}$, además del objetivo ilocutivo o la razón de ser ilocutiva de cada acto, se prestará atención a la dirección de adaptación, es decir, de las palabras al mundo o del mundo a las palabras ${ }^{154}$.

Los representativos (o asertivos) son aquellos actos lingǘsticos cuyo objetivo ilocutivo es comprometer al hablante con la verdad del contenido de la proposición hecha. Por ello, pueden ser sujetos al juicio de verdadero o falso. En esta categoría, los actos

\footnotetext{
${ }^{148}$ Además de ser compleja la medición de los efectos reales de un determinado texto bíblico sobre sus lectores, no corresponde al ámbito de la teología ni de la exégesis, seguramente lo será de la pastoral y/o la espiritualidad. 149 «Un acto lingüístico puede tener la fuerza de una orden, un consejo, una petición, una sugerencia o una descripción. La fuerza ilocutiva, que especifica el tipo de acción que se ha de seguir a través un enunciado, podría entonces ser descrita como el modo en que viene proferido un enunciado», Filippo Domaneschi, Introduzione alla pragmatica, 204.

${ }^{150}$ Véase John L. Austin, Cómo hacer cosas con palabras, 195-212; Filippo Domaneschi, Introduzione alla pragmatica, 209-211.

${ }^{151}$ Aunque se hace referencia al propósito del acto, Searle prefiere la expresión fuerza ilocutiva, porque resulta más amplia e integral, ya que el propósito solo vendría a ser una parte. John Searle, Expression and Meaning, 2 .

152 John Searle, Expression and meaning.12-20. Si bien no es la única propuesta de clasificación, diversos estudiosos han ofrecido otros criterios y, por lo tanto, otras clasificaciones, de las cuales hay una presentación sintética que hace Keith Allan en su artículo «Speech Act Classification and Definition», 922-926. Sin embargo, la propuesta de Searle ha tenido mayor acogida en el campo del análisis pragmalingüístico de la Escritura, y por tanto viene asumida en el presente artículo.

${ }^{153}$ Se sigue muy de cerca la síntesis que hizo Domaneschi sobre la clasificación de Searle. Filippo Domaneschi, Introduzione alla pragmatica, 223-225.

${ }^{154}$ John Searle, Expression and Meaning, 3-4; ver Carla Bazzanella, Linguistica e pragmatica del linguaggio, 159-160 y Filippo Domaneschi, Introduzione alla pragmatica, 221-222. Si bien es cierto, Searle también dará especial relevancia a un tercer criterio de clasificación, el estado psicológico que expresa, entre una docena que él identificó. John Searle, Expression and Meaning, 5; en la práctica, este último no ha sido asumido en la aplicación del análisis pragmalingüístico a la Escritura. Resultará, por obvias razones, ser de una amplia consideración por la aproximación de tipo psicológico al estudio de la Biblia. Además, se trata de un criterio que no siempre es claro en los cinco tipos de actos lingüísticos, y más bien es lo que caracteriza una categoría específica de ellos, los actos expresivos. John Searle, Expression and Meaning, 15.
} 


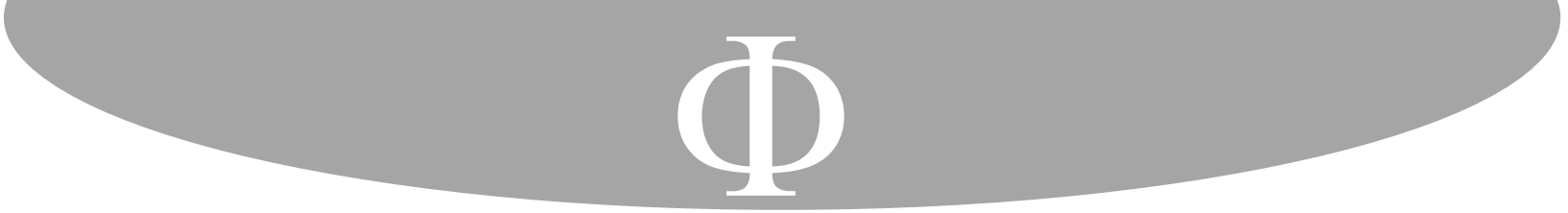

No porque en su ausencia no puedan darse ejercicios aplicativos, porque de hecho son numerosos (monografías, tesis, artículos, libros o partes de libros), sino porque en el análisis comparativo con todos ellos, afloran con mayor claridad los aspectos verdaderamente esenciales y prácticos que se requieren, se explora toda su riqueza metodológica y se consolida la identidad del proceso. Incluso, haciendo posible una sana discusión sobre sus componentes, y eventuales variantes por circunstancias de orden geográfico, cronológico, cultural o de otra índole.

\section{Bibliografía}

Alter, Robert. The art of Biblical Narrative. New York: Basic Books, 1981.

Austin, John L. Cómo hacer cosas con palabras. Palabras y acciones. Barcelona: Paidós, 1991 (Original inglés: How to Do Things with Words, 1962).

Barthes, Roland. «La mort de l'auteur». En Le bruissement de la langue, Essais critiques IV, 61-67. Paris: Seuil, 1984 (Publicado originalmente en Mantéia 5 (1968): 12-17).

Bazzanella, Carla. Linguistica e pragmatica del linguaggio. Un introduzione. Roma-Bari: GLF Laterza, 2007.

Berge, K. «Comunication». En Concise Encyclopedia of Pragmatics, editado por Jacob L. Mey, 140-147. Oxford: Elsevier Science, 1998.

Berges, Ulrich. «La lingüística pragmática como método de la exégesis bíblica». Revista Teológica limense 27 (1993): 64-90.

Berges, Ulrich. «Lectura pragmática del Pentateuco: Babel o el fin de la comunicación». Estudios Bíblicos 52 (1994): 63-94.

Bianchi, Claudia. Pragmatica del linguaggio. Bari: Laterza, 2010.

Bianchi, Claudia. La dipendenza contestuale. Per una teoria pragmatica del significato. Napoli: Edizioni Scientifiche Italiane, 2001.

Bianchi, Claudia. «Context off Utterance and Intended context». En Modeling and Using Context. Third International and Interdisciplinary Conference, Context 2001, editado por Varol Akman, Paolo Bouquet, Richmon Thomason y Roger A. Young, 73-86. Berlin Heidelberg: Springer-Verlag, 2001.

Bianchini, Francesco. L'analisi retorica delle lettere paoline. Milano: San Paolo, 2011.

Blenkinsopp, Joseph. El Pentateuco. Estella: Verbo Divino, 2014 (Original inglés: The Pentateuch, 1992).

Carrió, Genaro y Eduardo Rabossi. «La Filosofía de John L. Austin». Cómo hacer cosas con palabras. Palabras y acciones, por John L. Austin, 9-35. Barcelona: Paidós, 1991.

Concilio Vaticano II. Constitución pastoral Gaudium et Spes. Vaticano: Vaticano, 1965.

Concilio Vaticano II. Constitución pastoral Dei Verbum. Vaticano: Vaticano, 1965.

Dillmann, Rainer. «Consideraciones en torno a la pragmática». En Lectura pragmalingüística de la Biblia. Teoría y aplicación, por César Mora Paz, Massimo Grilli y Rainer Dillmann, 59-74. Estella: Verbo Divino, 1999.

Domaneschi, Filippo. Introduzione alla pragmatica. Roma: Carocci editore, 2014.

Eco, Umberto. Lector in fabula. La cooperación interpretativa en el texto narrativo. Barcelona: Lumen, 1981 (Original italiano: 1979)

Eco, Umberto. Seis paseos por los bosques narrativos. Barcelona: Lumen, 1996. (Original inglés: Six walks in the fictional Woods, 1994). 


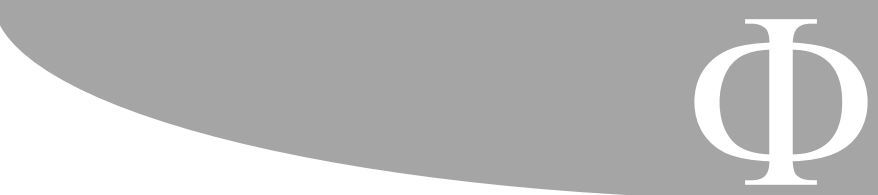

Rincón, Alfonso. «La Biblia en la encrucijada de múltiples lecturas». En A la luz y al servicio de la Palabra, homenaje al P. Pedro Ortiz Valdivieso, S.J., compilado por José Alfredo Noratto, 45-61. Bogotá: Facultad de Teología. PUJ, 2006.

Scott, Willim. Guía para el uso de la BHS. Aparato crítico, masora, acentos, letras poco comunes y otros signos. Vallejo: BIBAL Press, 1993. (Original inglés: 1977).

Searle, John. Expression and Meaning. Studies in the Theory of Speech Acts. New York: Cambridge University Press, 1986.

Simian-Yofre, Horacio. «Acronía. Los métodos estructuralistas». En Metodología del Antiguo Testamento, editado por Horacio Simian-Yofre, 127-143. Salamanca: Sígueme, 2001.

Simian-Yofre, Horacio. «Diacronía. Los métodos histórico-críticos». En Metodología del Antiguo Testamento, editado por Horacio Simian-Yofre, 83-125. Salamanca: Sígueme, 2001.

Simian-Yofre, Horacio. Ed. Metodología del Antiguo Testamento. Salamanca: Sígueme, 2001.

Simian-Yofre, Horacio. «Pragmalingüística: comunicación y exégesis». Revista Bíblica 30/31 (1988): 75-95.

Ska, Jean-Louis. «Sincronía. El análisis narrativo». En Metodología del Antiguo Testamento, editado por Horacio Simian-Yofre, 145-176. Salamanca: Sígueme, 2001.

Sonnet, Jean-Pierre. «L'analisi narrativa dei racconti biblici». En Manuale di esegesi dell'Antico Testamento. Compilado por Michaela Bauks y Christophe Nihan, 45-86. Bologna: EDB, 2010.

Theobald, Christoph. «Seguendo le orme...» della Dei Verbum. Bibbia, teologia e pratiche di lettura. Bologna: Edizioni Dehoniane Bologna, 2011 (Original francés: "Dans les traces..." de la constitution "Dei Verbum" du concile Vatican II. Bible, théologie et pratiques de lecture, Paris, 2009).

Tonelli, Debora. Imagini di violenza divina nell'Antico Testamento. Bologna: Edizioni Dehoniane Bologna, 2014.

Weinrich, Harald. Estructura y función de los tiempos en el lenguaje. Madrid: Gredos, 1968 (Original alemán: Tempus. Besprochene und Erzählte Welt, Stuttgart, 1964).

Enviado: 16 de marzo de 2021 Aceptado: 23 de abril de 2021 